but personally, looking through the bronchoscope or at bronchotomy, I have never seen anything whiter than a light pink. The majority have been red, some very red, emphasizing their vascularity.

I would like to comment on one or two other points. The statement that the mass that projects into the bronchial lumen is only a small part of a more extensive tumour needs modification. It may be and usually is, and is manifestly so in large tumours, but in some cases the tumour does not extend through the whole thiokness of the bronchial wall. I have on three occasions resected a tumour via a bronchotomy withour excising the whole thickness of the bronchial wall. Two of the patients are free from recurrence 14 and 16 years later and the third was lost sight of after four years when he emigrated.

Finally, I am in no way qualified to express an opinion on the histology, but I have the impression that the boundary between bronchial adenoma and adenocarcinoma may be hazy and that pathologists do not always speak with the same voice. A tumour which some would classify as an adenoma may be classified as an adenocarcinoma by others. The histological report in the three cases mentioned above was "benign bronchial adenoma," and I see no reason to suspect that the reports were incorrect.

It seems to me that there is still need for further study before we can approach the treatment of bronchial tumour with complete confidence. If we regard all of them as malignant or potentially so we shall avoid the surgical error of treating a malignant lesion as though it were a benign one, but will we avoid the surgical misfortune of treating a benign lesion as though it were a malignant one? - I am, etc.,

Midhurst, Sussex

VINCENT POWELI

\section{Haematology and Biochemistry of} Ankylosing Spondylitis

SIR,-Dr. M. J. Kendal and others (28 April, p. 235) state that the relatively high values of haemoglobin and serum albumin in their patients were unexpected. It is, however, well known that patients with ankylosing spondylitis have much less tendency to anaemia than rheumatoid patients and that, when present, the degree of anaemia is seldom severe. For example, in their study of 212 patients Wilkinson and Bywaters ${ }^{1}$ found mild anaemia in only 12. Admittedly, however, some authors (for example Lefcovitz and Thomas) have noted a higher incidence. In practice a moderate degree of anaemia in spondylitis always warrants a search for complicating factors, especially gastrointestinal bleeding from drug therapy.

Slight elevations of serum alkaline phosphatase may occur in ankylosing spondylitis especially when radiological changes are advanced. ${ }^{3}$ However, it is not generally accepted that this can be the result of bony ankylosis, as is suggested. The elevations are always very slight, and indeed in the present series the mean level of alkaline phosphatase (13.33 units) is only at the upper limit of normal and (as is pointed out) does not differ significantly from the mean alkaline phosphatase (11.77 units) of the rheumatoid group.

While it is true that the E.S.R does not correlate with the degree of, and is not often a reliable guide to, disease activity, it is misleading to say that this investigation is "of little value" in ankylosing spondylitis. Even moderate elevations of the E.S.R. may be helpful in the diagnosis of the early case. Moreover, the authors give the normal range of the E.S.R. as 0-12 m.m/1 hr. Most rheumatologists take a higher figure as the upper normal limit-up to $15 \mathrm{~mm} / 1 \mathrm{hr}$ in young males and $20 \mathrm{~mm} / 1 \mathrm{hr}$ in young females (even higher upper limits of normal are accepted in the elderly). Therefore the statement that "the E.S.R. was moderately raised in most patients" must be regarded with some reserve. In a few severe cases of ankylosing spondylitis the E.S.R. is very high and these patients do often have considerable pain; they are ill, wasted, and often respond poorly to conventional treatment with antiinflammatory drugs or deep $x$-rays. A continued high E.S.R. can therefore be of some prognostic significance.

Regarding serum protein electrophoresis in spondylitis, it is worth adding that when immunoelectrophoresis is carried out in addition to conventional electrophoresis a much higher frequency of abnormalities is found. In 10 consecutive patients of mine paper electrophoresis showed abnormalities in only two, whereas immunoelectrophoresis showed abnormalities of one or more of IgA, IgG, and IgM immunoglobulins in half the group. From the point of view of early diagnosis this would seem to merit further study. When IgG antiglobulins are considered, elevated levels are found in the majority of patients as in other varieties of seronegative polyarthritis, but this is a more difficult investigation to carry out routinely.-I am, etc.,

Princess Alexandra Hospital,

D. N. Goldng

1 Wilkinson, M., and Bywaters, B. G. L., Annals of the Rheumatic Diseases, $1958,17,209$. 3 Mowbray, Redicine, 1958, 49, 89. . J. H., Quarterly foumal of Medicine, 1949, 18, 4 Howeil, F. A., Chamberlain, M. A., Perry R. A., Torrigiani, G., and Roitt, I. M.;, Annals
of the Rheumatic Diseases, 1972, 31, 129.

\section{Amyloidosis and the Kidney}

SIR,-It is a pity that your leading article on amyloidosis and the kidney (12 May, p. 322) conveyed the impression that the body organs are equally affected in primary and secondary amyloidosis, discounting the traditional view that this is not so. The assertions may be true for the kidney, heart, and alimentary tract but they certainly do not apply to skin.

Clinical involvement of the skin in secondary amyloidosis is rare, whereas it is common in the primary form and in association with myeloma. About a quarter of these patients have curaneous lesions which are sufficiently characteristic to allow a firm clinical diagnosis in anticipation of biopsy confirmation. Translucent brown papules about the eyelids are often haemorrhagic. Sometimes larger but similar nodules appear on the face and lips. Diffuse infiltration of the fingers and hands (sometimes inducing haemorrhagic pseudobullae) leads to an appearance which may be mistaken for scleroderma.

These and other physical signs may lead *Most patients developed more than one symptom to recognition of the primary and myelomaassociated forms of amyloid by the dermatologist in patients with a variety of chronic systemic symptoms which have evaded previous diagnosis. -I am, etc.,

The London Hospital

HARVEY BAKER

\section{Supporting Service for the Mentally} Handicapped

SIR, - We wish to give our fullest support to Dr. E. B. MaDowall (26 May, p. 481) in his demand for a single responsible body to provide properly co-ordinated services for the mentally handicapped.

This is what is done in most other countries which have organized provision for medical care. Unless we follow their example the present trend of fragmentation of the provision of services will lead to an overall decrease in care as the mentally handicapped take their place at the foot of the priorities in each group providing these services-whether social, educational, or medical.

Care for the mentally handicapped requires to be comprehensive and prolonged, and to ensure this a specific responsible authority is required.-We are, etc.

\section{R. C. MACGILIIVRAY} Chairman

Lennox Castle Hospital

D. A. Primrose

Western Regional Division of Mental Deficiency The Royal Scottish National Hospital, Larbert, Stirlingshire

\section{Treatment of Status Asthmaticus}

SIR,-I read with great interest your leading article (9 December, 1972, p. 563), on the treatment of status asthmaticus. Though the administration of hydrocortisone (as well as aminophylline) is essential for the treatment, its use results in some untoward effects, some of which have never before been reported.

I have now finished a study of 31 patients admitted in status asthmaticus and treated with intravenous hydrocortisone. The first group of 15 patients included patients who had previously been on steroid treatment for chronic asthmatic bronchitis, and the initial intravenous dose of $\mathbf{2 0 0} \mathrm{mg}$ of hydrocortisone sodium phosphate did not give any side effects. The second group of 16 patients included patients who had never been on steroid treatment before, and the administration of $200 \mathrm{mg}$ of hydrocortisone sodium phosphate induced side affects which included paraesthesiae, ${ }^{1}$ macular rash, tremor of the arms and legs, and neausea and vomiting, as shown in the table. The duration Reaction

No. of

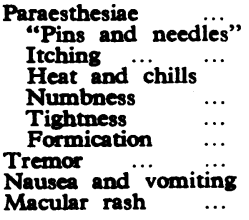

Patients 